\title{
From survival to survivorship: late side effects become an issue in high-grade glioma.
}

\author{
Yaacov R Lawrence \\ Thomas Jefferson University \\ Wenyin Shi \\ Thomas Jefferson University \\ Adam P Dicker \\ Thomas Jefferson University
}

\section{Follow this and additional works at: https://jdc.jefferson.edu/radoncfp \\ Part of the Oncology Commons, and the Radiology Commons \\ Let us know how access to this document benefits you}

\section{Recommended Citation}

Lawrence, Yaacov R; Shi, Wenyin; and Dicker, Adam P, "From survival to survivorship: late side effects become an issue in high-grade glioma." (2010). Department of Radiation Oncology Faculty Papers. Paper 17.

https://jdc.jefferson.edu/radoncfp/17

This Article is brought to you for free and open access by the Jefferson Digital Commons. The Jefferson Digital Commons is a service of Thomas Jefferson University's Center for Teaching and Learning (CTL). The Commons is a showcase for Jefferson books and journals, peer-reviewed scholarly publications, unique historical collections from the University archives, and teaching tools. The Jefferson Digital Commons allows researchers and interested readers anywhere in the world to learn about and keep up to date with Jefferson scholarship. This article has been accepted for inclusion in Department of Radiation Oncology Faculty Papers by an authorized administrator of the Jefferson Digital Commons. For more information, please contact: JeffersonDigitalCommons@jefferson.edu. 


\section{From survival to survivorship: late side effects become an issue in high-grade glioma}

Expert Rev. Neurother. 10(10), 1493-1495 (2010)
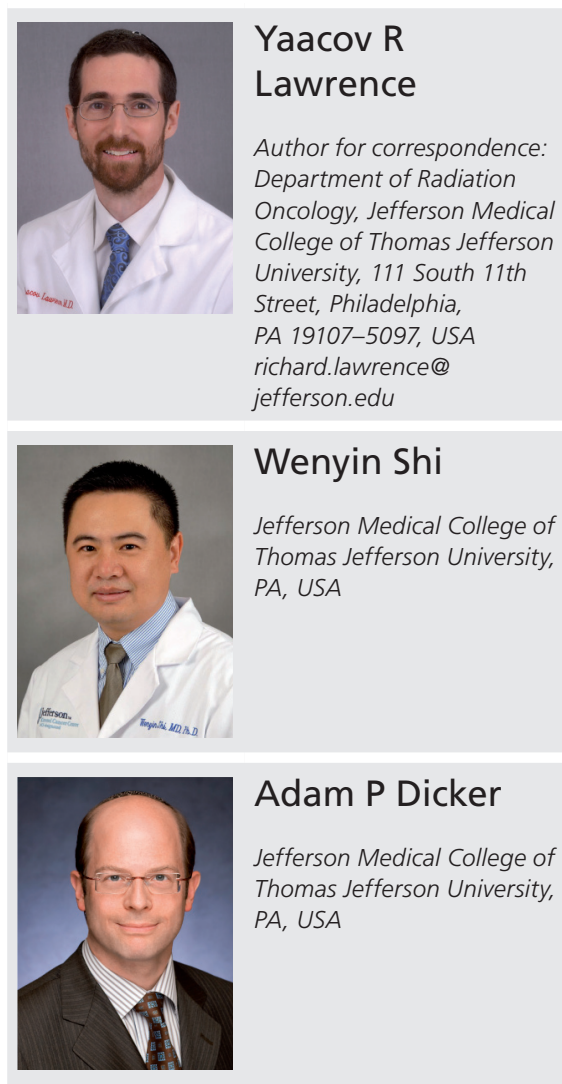

\author{
"For many patients, controlling neurological symptoms, \\ preventing cognitive dysfunction and maintaining functional \\ independence are just as important as prolonging survival."
}

Gliomas are the most common primary brain tumors. In adults, the most frequent subtype is glioblastoma, an aggressive and lethal tumor characterized histologically by frequent mitoses, rich angiogenesis and necrosis. Multimodality treatment is the standard of care: maximal safe resection followed by partial brain irradiation combined with temozolomide. Resection followed by radiation produces a median survival of 2-3 years in anaplastic astrocytoma [1], but only 5-12 months in patients with glioblastoma, depending on the population studied [2]. The addition of temozolomide, while only increasing median survival by 2.5 months [3], produces a marked increase in long-term survival, with $9.8 \%$ of patients who received combination treatment living 5 years, as opposed to $1.9 \%$ with radiation alone [4]. Longer survival is associated with host factors (performance status and age [5]), molecular characteristics $\left(O^{6}\right.$-methylguanine-DNA methyltransferase [MGMT] methylation [6], isocitrate dehydrogenase mutations [7] and polymorphisms in DNA repair enzymes [8]), and treatment factors (more radical resection [9] and use of temozolomide [4]). The cardinal non-molecular factors have been combined to define the Radiation Therapy Oncology Group (RTOG) recursive partitioning analysis class [5].

There is circumstantial evidence that survival may be improving further - in recent single-arm trials run by the New
Approaches to Brain Tumor Therapy Consortium, median survival was nearly 20 months [10]. Whether this survival increase is a reflection of the activity of the various therapeutic agents tested, the results of a more aggressive approach, the increased use of second- and third-line treatments or some other factor is not clear. The expectation is that newer therapies will further lengthen survival. As glioblastoma shifts from being a rapidly fatal to slowly progressive disease, we are obligated to consider the long-term side effects of present and future treatments. In addition to the 'classical' side effects, such as neurological deficits and brain necrosis, research now emphasizes neurocognitive function and quality of life. These 'newer' end points are complex, since both the tumor and the treatment impact upon them.

The long-term effects of radiation on the brain have been well described [11-14]. Pathological changes range from transient demyelination to irreversible vascular damage with resultant necrosis. A recent meta-analysis suggested that the brain is able to tolerate high doses of ionizing radiation (approximately 70 Gy) before undergoing necrosis [15]; however, more subtle cognitive changes occur at lower doses. Memory deficits following irradiation follow a biphasic pattern - in the initial months an initial decrement with rebound, followed by a secondary permanent decline [16-18]. Radiation-induced 
neurocognitive impairment is especially noted in children [19-21] and patients with primary CNS lymphoma [22-24], possibly reflecting the use of neurotoxic methotrexate in the latter.

Cytotoxic chemotherapy alone may also induce cognitive impairment. This is best documented in breast cancer patients receiving adjuvant adriamycin-based chemotherapy $[25,26]$. Although impairment is generally subtle and intermittent on objective testing [27], a subset of patients exhibit more profound and sustained impairment [26]. Consequently, a potential concern is that temozolomide may be lengthening survival, but worsening neurocognitive function and quality of life. Reassuringly, there is evidence that this is not the case, at least for early time points: in a trial of temozolomide for recurrent glioblastoma, individuals who were progression-free on temozolomide at 6 months had improvement in quality of life [28]. Another study demonstrated that amongst patients with glioblastoma, temozolomide treatment is associated with prolonged functional independence [29]. Furthermore, the European Organization for Research on Treatment of Cancer/National Cancer Institute of Canada Phase III trial that established temozolomide as standard of care in grade IV gliomas on the basis of improved survival also assessed seven domains of health-related quality of life (HRQOL; fatigue, insomnia, emotional function, social function, future uncertainty, communication deficit and overall HRQOL) [30]. Variations during treatment and follow-up were not substantial; however, they nearly all showed some improvement. Overall there was little difference between the radiation alone and the combined radiation-temozolomide arms; subjects on the experimental arm experienced more gastrointestinal symptoms early on, but this was to be expected and quickly improved following the cessation of temozolomide. Unfortunately the study had two limitations: firstly, due to dwindling numbers, only HRQOL data from the first year of follow-up was analyzed; secondly, neurocognitive function was not formally tested during follow-up. However, there is some preliminary evidence that glioblastoma patients who survive for more than 3 years may fare less well, with $85 \%$ having at least one significant neurologic deficit [31].

Little is known about the long-term neurocognitive side effects of novel molecular targeting agents, such as monoclonal antibodies, small molecular inhibitors and immunotherapy. Interestingly, early phase clinical trial data suggest that bevacizumab (VEGF antibody) can stabilize neurocognitive function and reduce reliance on steroids, improving day-to-day life for patients with recurrent glioblastoma [32].

Treatment side effects amongst glioma sufferers may not only be unpleasant, they may also impinge upon prognosis. By analyzing the side effects experienced by subjects previously enrolled on RTOG high-grade glioma trials, we were able to define risk factors for both acute (age greater than 50 years, poor performance status, more aggressive surgery, poor neurological function, poor mental function and twice-daily radiation) and chronic (once-daily radiation, use of chemotherapy, previous acute neurologic toxicity and total radiation dose) neurologic toxicity. The presence of acute neurologic toxicity was also found to predict poor overall survival, independent of recursive partitioning analysis class (median survival 7.8 vs 11.8 months; $\mathrm{p}<0.0001$ ) [33].

We do not know what the impact of new experimental agents on normal tissue function will be, whether used alone or together with radiation therapy. International cooperative groups led by the European Organization for Research on Treatment of Cancer and the RTOG have led the way in incorporating quality of life and neurocognitive end points into clinical trials; unfortunately, only a proportion of patients seen in the clinic are typically eligible for such trials. Only by bringing neuropsychological testing into daily practice will we be able to capture information on 'real patients' (those with poor performance status, elderly, ethnic minorities) that rarely enroll onto clinical trials. Standardized neuropsychological tests are reliable and valid measures when used correctly. When selecting neuropsychological tests, it is recommended to focus on specific domains of functioning, such as short-term memory; that tests be re-administered repeatedly in order to estimate variance and account for the 'training effect'; and finally that only standardized tests with documented reliability and validity are chosen [34]. Although formal neuropsychological tests are considered to be the 'gold standard', the associated logistical costs and staff training required hamper their widespread adoption. Computerized testing, such as provided by CogState ${ }^{\circledR}$ (CogState Ltd, Melbourne, Australia), may help overcome these hurdles [35].

\section{"Little is known about the long-term} neurocognitive side effects of novel molecular targeting agents, such as monoclonal antibodies, small molecular inhibitors and immunotherapy."

Patients with high-grade gliomas desperately require more effective interventions. For many patients, controlling neurological symptoms, preventing cognitive dysfunction and maintaining functional independence are just as important as prolonging survival. As new innovative therapies that seek to extend survival in this devastating disease are investigated, it is critical that we also evaluate their possible negative impact on functional outcomes over the long-term.

\section{Financial \& competing interests disclosure}

Yaacov $R$ Lawrence is supported by the American Society of Clinical Oncology Cancer Foundation Young Investigator Award. Any opinions, findings and conclusions expressed in this material are those of the author(s) and do not necessarily reflect those of the American Society of Clinical Oncology or the American Society of Clinical Oncology Cancer Foundation. Adam P Dicker is supported by NIH Grant CA10663, Tobacco Research Settlement Fund (State of Pennsylvania), and the Christine Baxter Fund. The authors have no other relevant affiliations or financial involvement with any organization or entity with a financial interest in or financial conflict with the subject matter or materials discussed in the manuscript apart from those disclosed.

No writing assistance was utilized in the production of this manuscript. 


\section{References}

1 DeAngelis LM. Brain tumors. N. Eng. J. Med. 344, 114-123 (2001).

-2 Ohgaki H, Kleihues P. Population-based studies on incidence, survival rates, and genetic alterations in astrocytic and oligodendroglial gliomas. J. Neuropathol. Exp. Neurol. 64, 479-489 (2005).

- 3 Stupp R, Mason WP, van den Bent MJ et al. Radiotherapy plus concomitant and adjuvant temozolomide for glioblastoma. N. Eng. J. Med. 352, 987-996 (2005).

\4 Stupp R, Hegi ME, Mason WP et al. Effects of radiotherapy with concomitant and adjuvant temozolomide versus radiotherapy alone on survival in glioblastoma in a randomised Phase III study: 5-year analysis of the EORTC-NCIC trial. Lancet Oncol. 10, 459-466 (2009).

-5 Curran WJ Jr, Scott CB, Horton J et al. Recursive partitioning analysis of prognostic factors in three Radiation Therapy Oncology Group malignant glioma trials. J. Natl Cancer Inst. 85, 704-710 (1993).

-6 Krex D, Klink B, Hartmann C et al. Long-term survival with glioblastoma multiforme. Brain 130, 2596-2606 (2007)

7 Weller M, Felsberg J, Hartmann C et al. Molecular predictors of progression-free and overall survival in patients with newly diagnosed glioblastoma: a prospective translational study of the German Glioma Network. J. Clin. Oncol. 27, 5743-5750 (2009).

-8 Liu Y, Shete S, Etzel CJ et al. Polymorphisms of LIG4, BTBD2, HMGA2, and RTEL1 genes involved in the double-strand break repair pathway predict glioblastoma survival. J. Clin. Oncol. 28, 2467-2474 (2010).

-9 Felsberg J, Rapp M, Loeser S et al. Prognostic significance of molecular markers and extent of resection in primary glioblastoma patients. Clin. Cancer Res. 15, 6683-6693 (2009).

- 10 Grossman SA, Ye X, Piantadosi S et al. Survival of patients with newly diagnosed glioblastoma treated with radiation and temozolomide in research studies in the United States. Clin. Cancer Res. 16, 2443-2449 (2010).

- 11 al-Mefty O, Kersh JE, Routh A, Smith RR. The long-term side effects of radiation therapy for benign brain tumors in adults. J. Neurosurg. 73, 502-512 (1990).

- 12 Armstrong CL, Gyato K, Awadalla AW, Lustig R, Tochner ZA. A critical review of the clinical effects of therapeutic irradiation damage to the brain: the roots of controversy. Neuropsychol. Rev. 14, 65-86 (2004).
13 Balducci M, Mattiucci GC, Dinapoli N et al. Impact of dose and volume on the tolerance of central nervous system. Rays 30, 189-195 (2005).

-14 Chong VF, Khoo JB, Chan LL, Rumpel H. Neurological changes following radiation therapy for head and neck tumours. Eur. J. Radiol. 44, 120-129 (2002).

15 Lawrence YR, Li XA, el Naqa I et al. Radiation dose-volume effects in the brain. Int. J. Radiat. Oncol. Biol. Phys. 76, S20-S27 (2010).

16 Armstrong C, Ruffer J, Corn B, DeVries K Mollman J. Biphasic patterns of memory deficits following moderate-dose partialbrain irradiation: neuropsychologic outcome and proposed mechanisms. J. Clin. Oncol. 13, 2263-2271 (2995).

17 Movsas B. Phase III study of prophylactic cranial irradiation (PCI) versus observation in patients with stage III non-small cell lung cancer (NSCLC): neurocognitive and quality of life (QOL) analysis of RTOG 0214. In: Annual Meeting of American Society for Radiation Oncology, Chicago, IL, USA, 1-5 November 2009.

- 18 Douw L, Klein M, Fagel SS et al. Cognitive and radiological effects of radiotherapy in patients with low-grade glioma: long-term follow-up. Lancet Neurol. 8, 810-818 (2009).

- 19 Brown RT, Madan-Swain A, Walco GA et al. Cognitive and academic late effects among children previously treated for acute lymphocytic leukemia receiving chemotherapy as CNS prophylaxis. J. Pediatr. Psychol. 23, 333-340 (1998).

$>_{20}$ Duffner PK. Long-term effects of radiation therapy on cognitive and endocrine function in children with leukemia and brain tumors. Neurologist 10, 293-310 (2004).

-21 Ellenberg L, McComb JG, Siegel SE, Stowe S. Factors affecting intellectual outcome in pediatric brain tumor patients. Neurosurgery 21, 638-644 (1987).

-22 Correa DD, DeAngelis LM, Shi W, Thaler H, Glass A, Abrey LE. Cognitive functions in survivors of primary central nervous system lymphoma. Neurology 62, 548-555 (2004).

-23 Harder H, Holtel H, Bromberg JE et al. Cognitive status and quality of life after treatment for primary CNS lymphoma. Neurology 62, 544-547 (2004).

-24 Schlegel U, Pels H, Oehring R, Blumcke I. Neurologic sequelae of treatment of primary CNS lymphomas. J. Neurooncol. 43, 277-286 (1999).
-25 Vardy J, Rourke S, Tannock IF. Evaluation of cognitive function associated with chemotherapy: a review of published studies and recommendations for future research. J. Clin. Oncol. 25, 2455-2463 (2007).

26 Stewart A, Bielajew C, Collins B, Parkinson M, Tomiak E. A meta-analysis of the neuropsychological effects of adjuvant chemotherapy treatment in women treated for breast cancer. Clin. Neuropsychol. 20, 76-89 (2006).

Vardy J, Wefel JS, Ahles T, Tannock IF, Schagen SB. Cancer and cancer-therapy related cognitive dysfunction: an international perspective from the Venice cognitive workshop. Ann. Oncol. 19, 623-629 (2008).

- 28 Osoba D, Brada M, Yung WK, Prados M. Health-related quality of life in patients treated with temozolomide versus procarbazine for recurrent glioblastoma multiforme. J. Clin. Oncol. 18, 1481-1491 (2000).

29 Chaichana KL, Halthore AN, Parker SL et al. Factors involved in maintaining prolonged functional independence following supratentorial glioblastoma resection. J. Neurosurg. DOI: 10.3171/2010.4.JNS091340 (2010) (Epub ahead of print).

30 Taphoorn MJ, Stupp R, Coens C et al. Health-related quality of life in patients with glioblastoma: a randomised controlled trial. Lancet Oncol. 6, 937-944 (2005).

31 Hottinger AF, Yoon H, DeAngelis LM, Abrey LE. Neurological outcome of long-term glioblastoma survivors. J. Neurooncol. 95, 301-305 (2009).

- 32 Chamberlain MC. Emerging clinical principles on the use of bevacizumab for the treatment of malignant gliomas. Cancer 116(17), 3988-3999 (2010).

33 Lawrence YR, Wang M, Dicker A et al. Acute neurological toxicity (NT) and long-term outcomes in high-grade glioma RTOG trials. J. Clin. Oncol. 28(Suppl. 1), abstract 2037 (2010).

34 Baschnagel A, Wolters P, Camphausen K. Neuropsychological testing and biomarkers in the management of brain metastases. Radiat. Oncol. 3, 26 (2008).

\$35 Falleti MG, Maruff P, Collie A, Darby DG. Practice effects associated with the repeated assessment of cognitive function using the CogState battery at 10-minute, one week and one month testretest intervals. J. Clin. Exp. Neuropsychol. 28, 1095-1112 (2006). 